\title{
BOUNDING SOLUTIONS OF GEOMETRICALLY NONLINEAR VISCOELASTIC PROBLEMS
}

\section{ORIGINAL PAGE IS OF POOR QUALITY}

\author{
by \\ Johr in Stursidd arie: George J. Simitser.

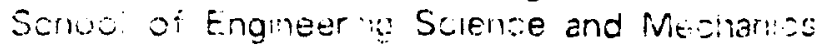

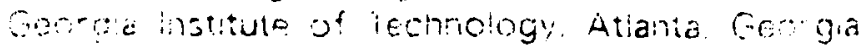 \\ A.bsiract
}

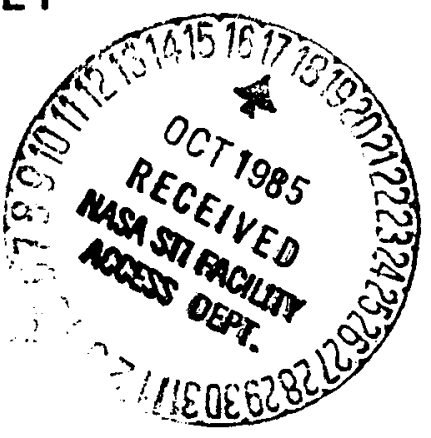

Integrat iransform teilingues such as the Laplase trarstorm provide simple and dreci metheds for solving viscoebasti oroblems cormulated viltir a context of linear materia responce ald us:rg irear measures to. deformation Aphication of the iranetarm operata reduces the

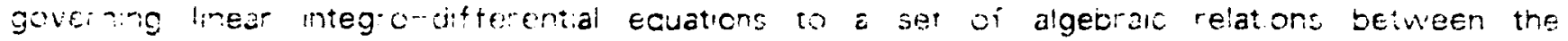

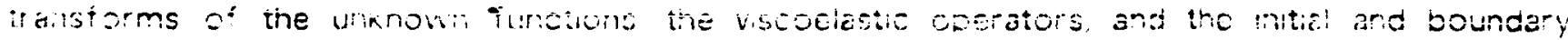

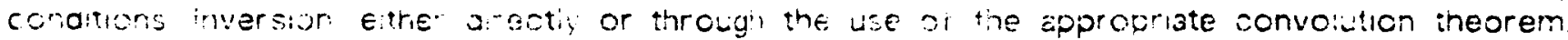

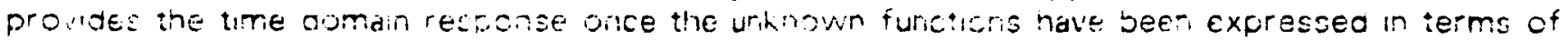

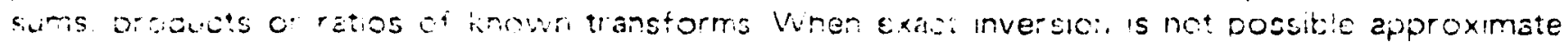

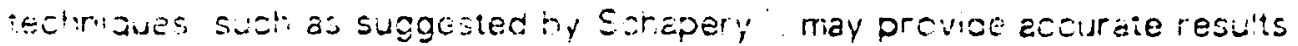

Ye over al problem becomes sucstantially more compex vituen nonirear effeats rnis: be riclused lae conside: here situations where a linear material conjtiturve lav can stil! be pisd.cive, emplo;ed but where the magnitude of the resulting time cependen: ceformations

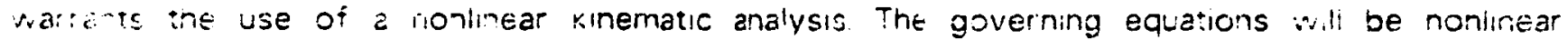
regro-ditierential equdtions for this class of probiems. 7 his traditiona: as weli as approximate iectrayes such az cited above cannot be empicyed since ine transform of a nonlinear functicn is roi expluitiy expressibie

Rogers and Lee: considered such a probiem in an investigation of the finite deflecticn of a viccoelastic cantilever beam. Employing an analogy to an associated elastic problem they cerived a s.jtian to the viscoelastic problem in a form involving a time convolution ci a nonlinear space ar.j t. me appendent integral iunction. Nurnerica! evaluation vias accomplished using Picard's method ci susessive sibstiutions. Nenton-Cotat cuadratures ware empioyfo to approximate the spatially deiversent integt al relaticnshif; a mean value based inite difference formuia was used for the tirie comolitian

Solution procedures of this type are generair will suted for conputer implementation. - W veve: riey can become compuationaly inefficient when the response must be cetermined cver : f:x:ended time period Eash increment in time requires a rea:labution of the convolution integrals "his sine entire deformation history must se ietained in memary during the caiculailons. Since each compieted set of computations adds another set of resuli: to this history this results in an ever acrasing rierrory requirement. in addion the rota rumber of computations which must be fer? =rmed during the sucseeding iteration is aiso increased.

$\therefore$ this regard an approximation technique proposed by Scnape:; ${ }^{3}$ ean piovide an attractive E:s-maive Commonly referred to as the "quas:-elastic" apprcximatiri. it nas most recentiy besh snployed ty v'mogradovit and vinogradov and Vijeweera's studes of the behavior ot eccentricaily loaded viscoelastic a antilever beams

The rethod is tasad on the observation that the solwion procedure developed by fogers and

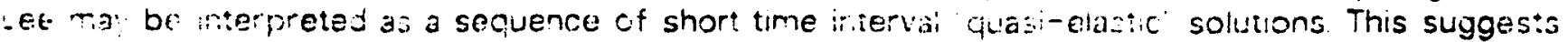
that afproximute solutions may be generated by replacing the arigini viscoelastic problem by ar: equivereft time dapendent elastic one in this replacament problem the elastic properties are equatce to the instantaneous values of the relaxiatio: moduit or creep compliances of the visoziastio mater al

- Giaduate Researsh Assistant, member ASME -

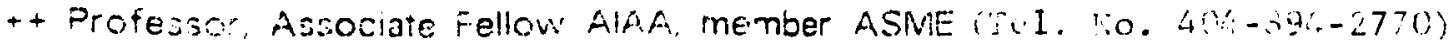

(NASA $-C D-176219)$ BOUNEING SOIUIIONS OF N86-19860

GEOAFTETCATIY NONIINEAR VISCOETASTIC

PCOBLFMS (Georgia Irst. of Eech.) $3 \mathrm{p}$

मC $122 / M F 1) 1$

CSCL 12A

!nclas

$63 / 6429170$ 


\section{ORIGINAL PAGE IS \\ OF POOR QUALITY}

The inherent numerical aovantage providea by this techiniqu is that it can eliminate the potentially inefficieni convolution integral calculations. Thus the speed and efficiency at which the time dapendent response is calculated will become independent of elapsed time The obvious potentia disadvantage of the techmique is that since it is an approximation significant differences inay exist between the actual response of the viscoelastic body and those predicted quas:-elastically. In addition, the quasi-elastic method does not provide a direct method for assessing whetner or not the errors which may be incurred are conservative.

In trus paper we demonstrate that the quasi-elastic approximation technique can be modified to praviae toth upper and lover bound preacions for the class of viscuelastic prublems under coneineration io accomplish th:s the solution of the actual viscceiastic pryolem is first formulated ir lerms of a Volterra type integral equation of the second kina Ar. uppe: or lower bound solution is then esiablished by replacing the desired unknown function which appears under the integral sign by an appropriate approximating function. The approximating function selected is one which inherent:y bounds the desired unk!nown function and is also independent of the integration variable The kerne! of the integrai operator can then be integrated formally casting the approximate problem into the typical quasi-elastic forma: Provided the kerriel of the origirial integral operator is positive semi-deftnite this quasi-elastic solution must bound the actua! solution in the same manner that the approximiating function bounded the desired uriknown func:ion

lllustrated on the following page are comparisons of resuits obiained using the bounding :echique io the exact sclution for the transverseiy ioaded viscoelastic cantilever beam problem considered by Rogers and Lee Additionai examples of the appiication of the technique. inciuding procedures to be used when nonlinear boundary terms appear in the original integra! equation, are provided in the paper.

\section{Acknowledgements}

This work was performed under NASA Grant No. NAG 3-534 The fimancia! suppcit frovided by NASA is gratefully acknowledged by the authors. Special thanks are extended to Dr C.C. Chamis of the NASA-Lewis Research Center for his encouragement and for the many meaningful and fruitful discussions.

\section{References}

1. Schapery. R.A., "Approximate Methods of Transform Inversion for Viscoelastic Stress Analysis". Proceedings "US Congress on Applied Miechanics, Vo!. 2, 1962, pF $1075-1085$

2 Foge-s. T.G. and Lee. E.H. "On the Finite Deflection of a Viscoelastic Cantilever", Piveeedings 4 U'S Congress on Applied Mechanics. Voi. 2, 1962. pp. 977-987

3 Schapery, RA., 'A Method of Viscoelastic Stress Anaiysis Using Elastic Solutions". Journal of the Franklin Institute, Vol. 279. No. 4, 1965. pp. 268-289

4. Vinogradov, AM., "Nonlinear Effects in Creep Buckling Anaiysis of Columns", Journal of Engineering Mechanics, ASCE, Vol 111. No. 6, 1985. pp 757-767

5 Vinogradov, A.M and Wijeweera. H. "Thecretical and Experimental Studies or Creep Buckling", 26". Structures, Structurai Dynamics and Materials Conference, Vol. 1. 1985. pp $160-164$ 


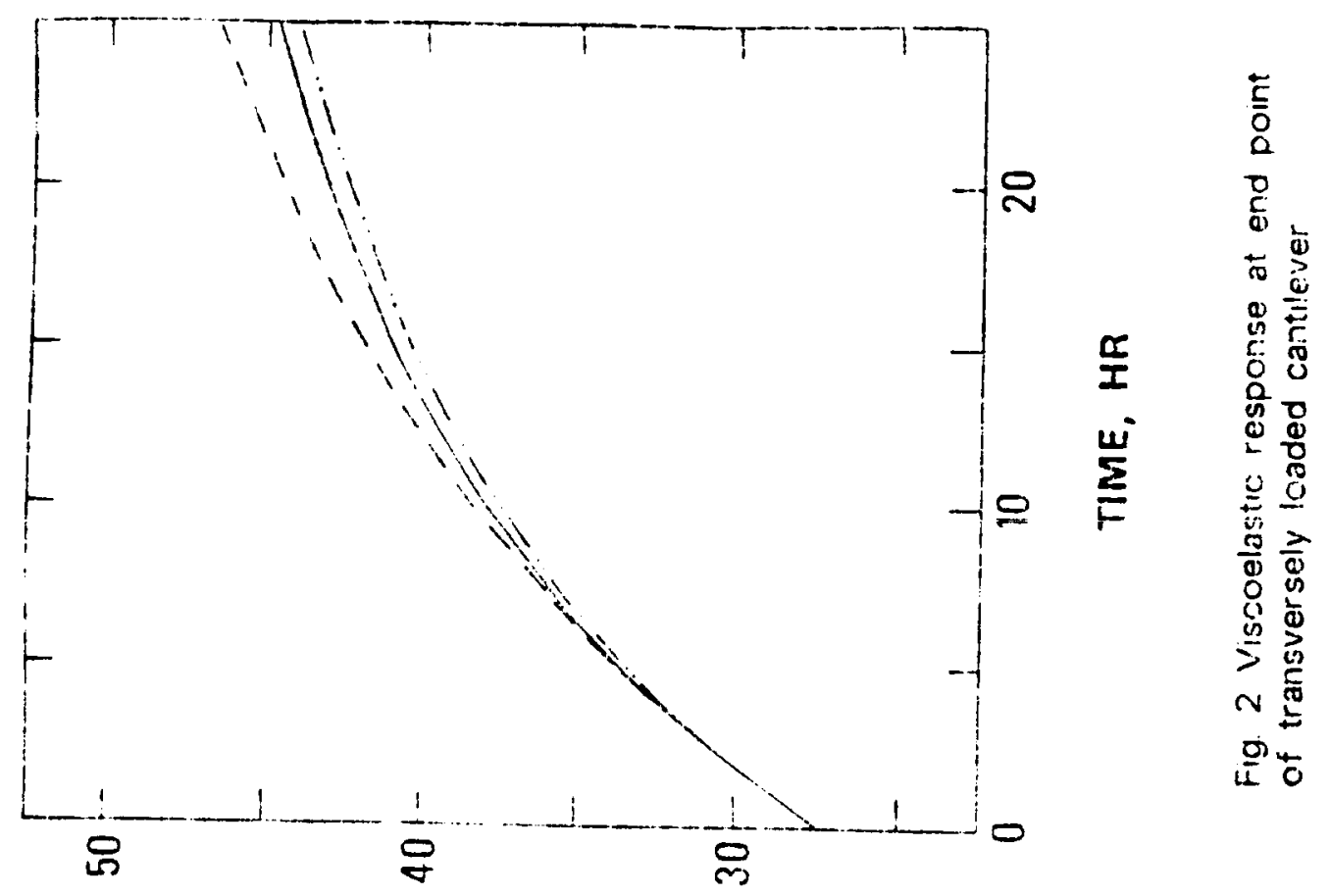

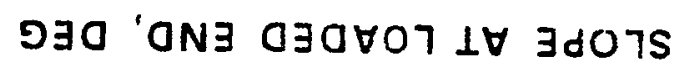

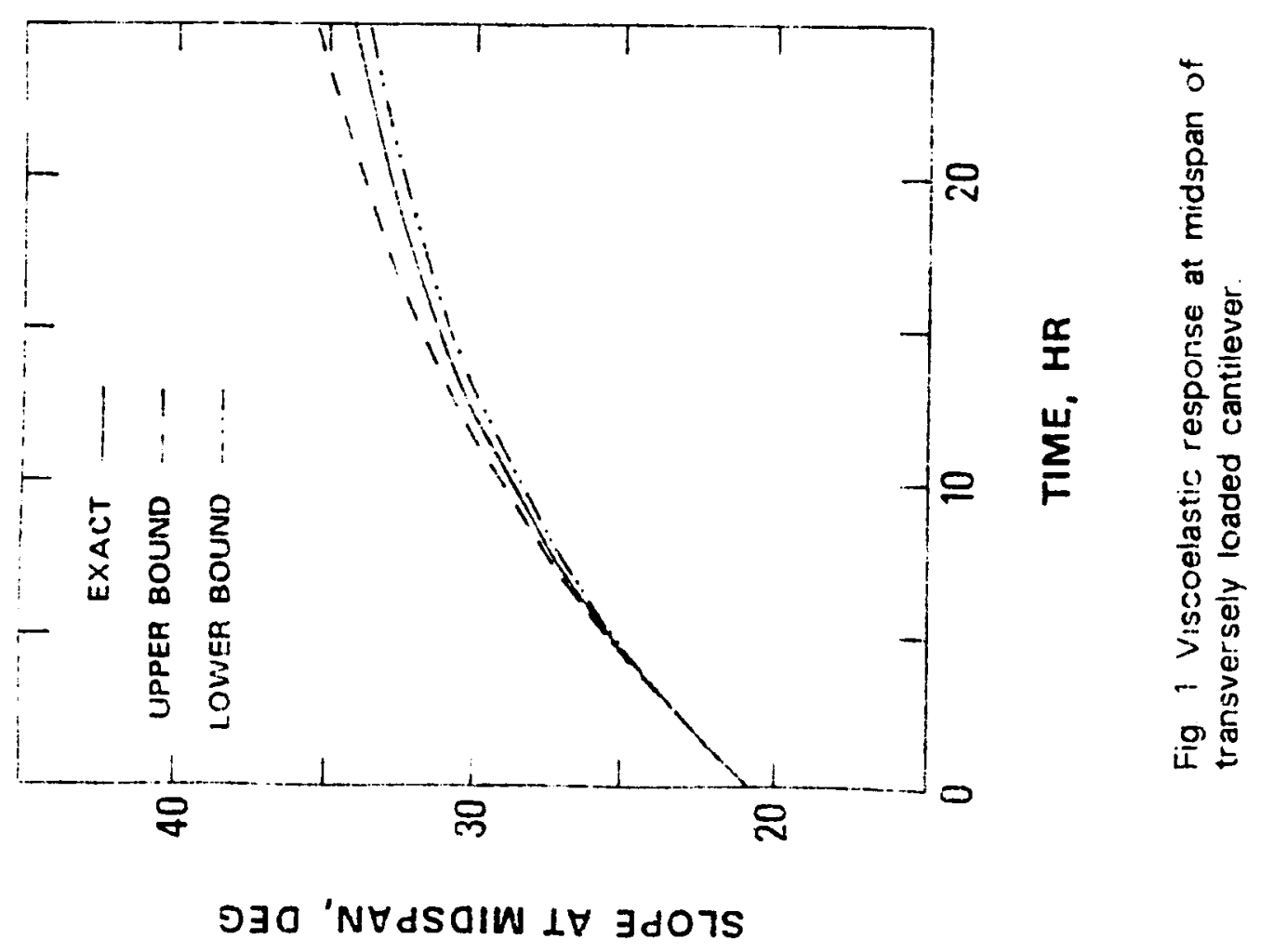

